\title{
Nursing procedures for advanced dementia: Traditional techniques versus autonomous robotic applications (Review)
}

\author{
LILIANA DAVID $^{1}$, STEFAN L. POPA ${ }^{1}$, MARIA BARSAN ${ }^{2}$, LUCIAN MURESAN $^{3}$, \\ ABDULRAHMAN ISMAIEL ${ }^{1}$, LUMINITA C. POPA ${ }^{4}$, LACRAMIOARA PERJU-DUMBRAVA ${ }^{4}$, \\ MIHAELA FADGYAS STANCULETE ${ }^{5}$ and DAN L. DUMITRASCU ${ }^{1}$
}

\author{
${ }^{1}$ Second Medical Department and ${ }^{2}$ Department of Occupational Health, 'Iuliu Hatieganu' University of \\ Medicine and Pharmacy, Cluj-Napoca 400000, Romania; ${ }^{3}$ Department of Cardiology, 'Emile Muller' Hospital, \\ Mulhouse, 68200 Mulhouse, France; ${ }^{4}$ Department of Neurosciences, Discipline of Neurology, 'Iuliu Hatieganu' \\ University of Medicine and Pharmacy; ${ }^{5}$ Department of Neurosciences, Discipline of Psychiatry and Pediatric Psychiatry, \\ 'Iuliu Hatieganu' University of Medicine and Pharmacy, Cluj-Napoca 400012, Romania
}

Received August 25, 2021; Accepted September 24, 2021

DOI: $10.3892 / \mathrm{etm} .2021 .11047$

\begin{abstract}
The purpose of this study was to perform a comparative analysis of traditional nursing techniques and autonomous robotic applications used for managing patients with advanced stages of dementia. PubMed, Cochrane Library, EMBASE, and WILEY databases were searched for relevant articles concerning nursing techniques applied in the treatment of patients with advanced dementia. The search terms included: (advanced dementia OR severe dementia) AND [artificial intelligence (AI) OR robotic OR robots OR neural networks OR deep learning OR automated procedures OR autonomous application]. This search identified a total of 2,679 articles and 298 articles were selected. Finally, 23 articles were included in this systematic review, out of which 8 studies analyzed traditional nursing techniques and 15 studies analyzed autonomous robotic applications. Significant evidence was revealed, demonstrating that autonomous robotic applications used for patients with advanced stages of dementia are a feasible, cost-efficient solution and represent an excellent benefit for patients and the healthcare system.
\end{abstract}

\section{Contents}

1. Introduction

2. Traditional nursing techniques for patients with advanced dementia

Correspondence to: Dr Stefan L. Popa, Second Medical Department, 'Iuliu Hatieganu' University of Medicine and Pharmacy, 2-4 Clinicilor Street, Cluj-Napoca 400000, Romania E-mail: popa.stefan@umfcluj.ro

Key words: advanced dementia, nursing, nursing procedures, artificial intelligence, robots, future of medicine
3. Autonomous Robotic Applications for patients with advanced dementia

4. Conclusions

\section{Introduction}

Dementia represents a major neurocognitive disorder caused by brain disease or injury and is characterized by impairments in executive function, learning and memory, attention, language, perceptual-motor function, and/or social cognition, among other psychiatric, mood, and behavioural disturbances (1).

Unfortunately, the onset of this disease may be very subtle, and patients frequently present unspecific symptoms that can be easily confused with chronic fatigue syndrome, depression, insomnia, anaemia, infections, side effects of medication, natural aging, nutrient imbalances, or vitamin and hormone deficiencies. For this reason, dementia is commonly misdiagnosed or overlooked in the earlier stages (1-5).

Since the average life expectancy has increased, dementia rates are rapidly growing in all continents (1). Epidemiologic studies revealed that $\sim 6 \%$ of the population over 65 years is diagnosed with dementia (1-5), and 46.8 million people live with dementia worldwide. Furthermore, the total number of patients with dementia is estimated to double every 20 years. There is no curative treatment for the disease, and the burden on society is significant (5).

The main nursing interventions for patients with advanced dementia include periodic change of position to avoid the appearance of pressure ulcers, active and passive mobilization, massage, passive feeding, skin hygiene, bed and body linen, bedding with flea and urinary catheter management. In the situation where these patients are immobilized in beds, it is necessary to prevent falls by properly arranging the space in the bed to eliminate safety risks. These procedures are used as an attempt to overcome complications of advanced dementia such as metabolic disorders related to nutritional deficiency, depression, self-injury and impaired self-image. Patients with 
advanced stages of dementia frequently require professional 24-h supervision for their personal safety, basic needs, and the administration of medication (1-5). Autonomous robotic assistive technology may represent an affordable and practical solution to this global problem.

For this reason, the purpose of this study was to perform a comparative analysis of traditional nursing techniques and autonomous robotic applications used on patients with advanced stages of dementia.

PubMed, Cochrane Library, EMBASE, and WILEY databases were searched for relevant articles regarding nursing techniques used in patients with advanced dementia, starting with traditional techniques and ending with artificial intelligence (AI)-based systems and autonomous robots. The search terms included: (advanced dementia OR severe dementia) AND (AI OR robotic OR robots OR neural networks OR deep learning OR automated procedures OR autonomous application).

Exclusion criteria were: conference presentations, letters to the editor, studies written in languages other than English, case reports, pediatric studies, abstracts, and editorials (Fig. 1). A total of 2 independent authors (LD and SLP) reviewed eligibility titles, abstracts, and full text of eligible articles. Data extraction was conducted independently by both reviewers. Fig. 1 demonstrates the search strategy using the PRISMA flow diagram.

Discrepancies related to the results of the quality assessment evaluation between the two investigators were resolved through discussion. Results of the methodological quality assessment did not have any effect on the eligibility of the studies in our systematic review.

Our search identified a total of 2,679 articles. Following use of human filters, the search identified 298 articles. Following application of all filters (human filters, while excluding conference abstracts and conference papers), 112 studies remained. Finally, a total of 23 articles were included in this systematic review: 8 studies analyzing traditional nursing techniques and 15 studies analyzing autonomous robotic applications.

\section{Traditional nursing techniques for patients with advanced dementia}

The articles that were selected mention the importance of traditional nursing techniques in different aspects of the multifaceted health problem that is dementia (Table I).

An extensive trial conducted by Husebo et al (6) evaluated the effects of a 4-step pain management protocol on agitation, aggression, pain, activities of daily life, and cognition in patients suffering from moderate to severe dementia and clinically significant behavioural changes. All patients were residents of one of the 60 single independent nursing home units included in the trial. The outcome was evaluated using multiple measuring tools: Cohen-Mansfield agitation inventory, neuropsychiatric inventory (nursing home version), mobilisation-observation-behaviour-intensity-dementia-2 pain scale, activities of daily life, and Mini-Mental State Examination (MMSE). The active intervention proved to be of great benefit in addition to the non-specific effect, and the authors suggested that well-coordinated pain management could be used extensively for the assistance of agitated residents of nursing homes suffering from dementia.

Following performance of a systematic review of enteral tube feeding in patients with advanced dementia, Sampson et al (7) concluded that the benefits are not supported by sufficient evidence despite numerous patients receiving this intervention. Concurrently, it appeared that the side effects of this procedure lacked adequate study.

A team led by Skovdahl et al (8) studied the effect of tactile stimulation in five residents from a nursing home who suffered from behavioural and psychiatric symptoms of dementia. The caregivers were instructed on performing tactile stimulation and applied this technique at least once a week. Each session was documented using a form designed specifically for this purpose. The entire documentation containing 60 pages was then analyzed using qualitative content analysis. The sessions designed to continue for 28 weeks with a mean duration of $45 \mathrm{~min}$ had a positive and relaxing influence, however, the use of such therapies should be respectful towards the preferences of patients.

The effect of music therapy was studied by Ridder et al (9) in an exploratory randomized controlled trial that compared the standard care group of patients with the groups receiving music therapy twice a week, for six weeks in a row. Music therapy demonstrated a positive effect on the quality of life and reduced agitation disruptiveness.

Murphy et al (10) analyzed the effects of palliative care interventions in patients with advanced dementia, but their systematic review identified only two completed studies that matched their criteria. These studies assessed different outcomes, making it impossible to draw any conclusion other than an imperative need for high-quality research on this subject.

Taking care of residents diagnosed with dementia may also take its toll on the nursing home staff. Aasmul et al (11) concluded that individual pain management in such patients would indirectly reduce staff distress with lasting effects. The research methodology included subjects from 60 nursing home units, where the primary caregivers had direct contact with the patient (highly agitated patients with advanced dementia) for at least four weeks.

Training programs for caregivers in medical settings could delay the admission of the patient to a nursing home, prove cost-efficient, and lessen the burden for the caregivers. This is what the researchers coordinated by Birkenhäger-Gillesse et al (12) are currently trying to demonstrate with a randomized controlled study protocol designed to examine the effects of a 5-day training program ('More at Home with Dementia') in an intervention group.

The effect of canine-assisted therapy on the quality of life of patients diagnosed with Alzheimer's type dementia was evaluated in a quasi-experimental study by Sanchez-Valdeon et al (13). The authors used specifically trained dogs in therapy sessions lasting $30 \mathrm{~min}$ and repeated once a week for 12 months. All the subjects experienced a positive influence on the quality of life [outcome assessed using the Quality of Life in Late-Stage Dementia (QUALID) scale]. The fact that the study included only a small number of participants prevents the extrapolation of the results. 

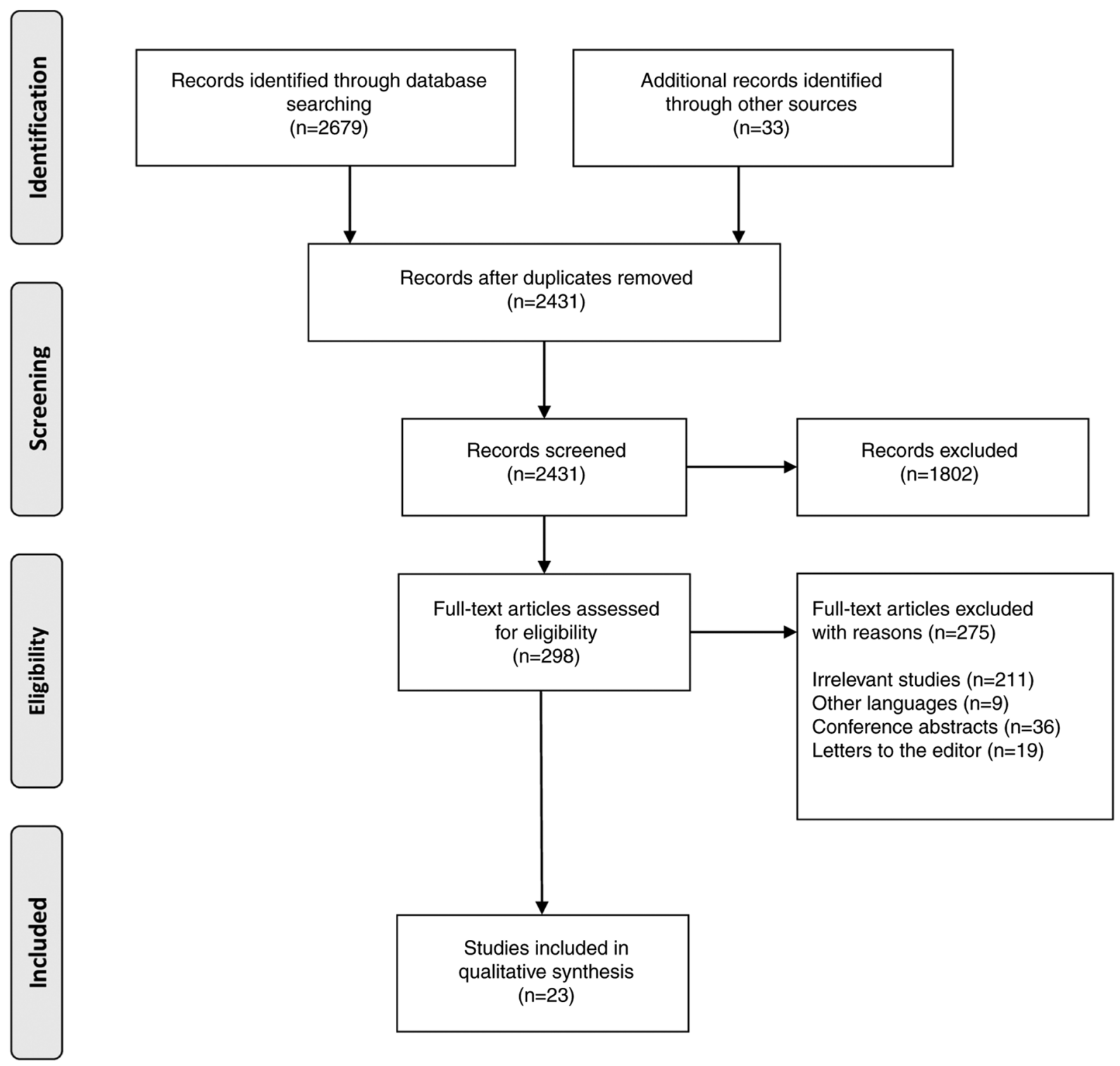

Figure 1. PRISMA flow diagram for study selection.

\section{Autonomous Robotic Applications for patients with advanced dementia}

Our search for studies concerning autonomous robotic applications used for patients with advanced dementia identified 15 studies (Table II).

In the study performed by Demange et al (14), it was demonstrated that the PARO ${ }^{\circledR}$ robot (Intelligent System Co.) was helpful in supporting the treatment of acute pain in 12 patients with dementia. The $\mathrm{PARO}^{\circledR}$ robot is a pet robot in the shape of a baby harp seal designed for psychological care in geriatric patients. It was previously successfully used to accompany the treatment of certain behavioural disorders, reducing loneliness, stress levels and improving communication and/or social behaviours in elderly patients with dementia. A total of $92 \%$ of the patients revealed a positive attitude toward the PARO robot, regardless of the type of painful situation (14).

Valentí et al (15) conducted a study in an elderly population group with dementia, comparing the effect of a humanoid robot (NAO), a pet robot (PARO), and a dog on behavioural changes, reduction of apathy, and improvement of quality of life. The study was conducted in a nursing home on 101 patients (Phase 1) who interacted either with the humanoid robot, with the pet robot, or received conventional therapy. In Phase 2 of the study, 110 patients interacted either with a dog, with the PARO robot, or received conventional therapy. In the day-care centre, 20 patients were included in Phase 1 and 17 patients in Phase 2. Concerning the patients from the nursing home, the authors revealed that in those from Phase 1, patients in the robot groups exhibited an improvement in apathy; patients in the NAO group exhibited a decline in cognition as assessed by the MMSE scores. The robot groups exhibited no significant changes between them. For patients included in Phase 2, the QUALID scale scores were increased in the PARO group. In the day-care centre, patients from Phase 1 revealed an improvement in the Neuropsychiatric Inventory-Questionnaire (NPI) irritability and total score (15). Patients from Phase 2 demonstrated no differences at follow-up (15). 
Table I. Traditional nursing techniques for advanced dementia patients.

\begin{tabular}{|c|c|c|c|c|c|}
\hline Author (Refs.) & Year & Evidence type & Method & Treatment & Outcome \\
\hline Husebo et al (6) & 2011 & $\begin{array}{l}\text { Cluster } \\
\text { randomized } \\
\text { controlled trial }\end{array}$ & $\begin{array}{l}\text { Patients with stepwise } \\
\text { pain treatment } \\
\text { protocol vs. control } \\
\text { group (patients with } \\
\text { usual management) }\end{array}$ & $\begin{array}{l}\text { Eight weeks of three times a day } \\
\text { pain medication according to a } \\
\text { 4-step protocol with a } 2 \text {-week } \\
\text { follow-up }\end{array}$ & $\begin{array}{l}\text { Efficient pain } \\
\text { management } \\
\text { significantly } \\
\text { reduces } \\
\text { agitation }\end{array}$ \\
\hline Sampson et al (7) & 2009 & $\begin{array}{l}\text { Systematic } \\
\text { review }\end{array}$ & $\begin{array}{l}\text { Inclusion of } \\
\text { observational studies in } \\
\text { the absence of } \\
\text { randomized controlled } \\
\text { trials }\end{array}$ & - & $\begin{array}{l}\text { Insufficient } \\
\text { evidence on the } \\
\text { benefits of tube } \\
\text { feeding; requirement } \\
\text { for further studies }\end{array}$ \\
\hline Skovdahl et al (8) & 2007 & Study & $\begin{array}{l}\text { Data was analyzed with } \\
\text { qualitative content } \\
\text { analysis }\end{array}$ & $\begin{array}{l}\text { Tactile stimulation in five } \\
\text { patients with moderate-to-severe } \\
\text { dementia and a tendency towards } \\
\text { aggression or restlessness }\end{array}$ & $\begin{array}{l}\text { Positive feelings and } \\
\text { relaxation }\end{array}$ \\
\hline Ridder et al (9) & 2013 & $\begin{array}{l}\text { Exploratory } \\
\text { randomized } \\
\text { controlled trial }\end{array}$ & $\begin{array}{l}\text { Music therapy vs. } \\
\text { standard care }\end{array}$ & $\begin{array}{l}\text { Six weeks of two times per week } \\
\text { individual music therapy sessions }\end{array}$ & $\begin{array}{l}\text { Decrease in } \\
\text { agitation and } \\
\text { improvement in } \\
\text { quality of life }\end{array}$ \\
\hline Murphy et al (10) & 2016 & $\begin{array}{l}\text { Systematic } \\
\text { review }\end{array}$ & $\begin{array}{l}\text { Only two studies } \\
\text { concerning palliative } \\
\text { care were considered; } \\
\text { meta-analysis of the } \\
\text { data was not possible }\end{array}$ & - & $\begin{array}{l}\text { Insufficient evidence } \\
\text { for evaluating the } \\
\text { influence }\end{array}$ \\
\hline Aasmul et al (11) & 2016 & $\begin{array}{l}\text { Cluster } \\
\text { randomized } \\
\text { controlled trial }\end{array}$ & $\begin{array}{l}\text { Caregivers for } \\
\text { patients in the } \\
\text { intervention group vs. } \\
\text { caregivers for patients } \\
\text { in the control group }\end{array}$ & $\begin{array}{l}\text { Individual pain treatment for } \\
8 \text { weeks, followed by a } 4 \text {-week } \\
\text { wash-out period }\end{array}$ & $\begin{array}{l}\text { Decrease of staff } \\
\text { distress in the } \\
\text { intervention group }\end{array}$ \\
\hline $\begin{array}{l}\text { Birkenhäger- } \\
\text { Gillesse et al (12) }\end{array}$ & 2018 & $\begin{array}{l}\text { Randomized } \\
\text { controlled study }\end{array}$ & $\begin{array}{l}\text { Dyads (patient and } \\
\text { caregiver) included } \\
\text { either in the } \\
\text { intervention group or in } \\
\text { the control group; data } \\
\text { collected at baseline, } \\
3 \text { months, and } 6 \text { months }\end{array}$ & $\begin{array}{l}\text { 'More at Home with Dementia' } \\
\text { training program for } 5 \text { days }\end{array}$ & $\begin{array}{l}\text { Focus on the } \\
\text { quality of life of the } \\
\text { caregiver at three } \\
\text { months and } \\
\text { neuropsychiatric } \\
\text { symptoms of the } \\
\text { patient }\end{array}$ \\
\hline $\begin{array}{l}\text { Sanchez- } \\
\text { Valdeon et al (13) }\end{array}$ & 2019 & Study & $\begin{array}{l}\text { Quasi-experimental; } \\
\text { pre-post case series } \\
\text { design; data collection } \\
\text { at start, following } \\
6 \text { months and following } \\
12 \text { months }\end{array}$ & $\begin{array}{l}12 \text { months of weekly } 30 \text {-min long } \\
\text { individual canine-assisted therapy }\end{array}$ & $\begin{array}{l}\text { Significant benefits } \\
\text { for quality of life }\end{array}$ \\
\hline
\end{tabular}

Simulated presence therapy is a type of intervention used in patients with dementia that uses audio or video recordings of family members that are played to the person with dementia. Its potential role in improving behavioural and psychological symptoms and quality of life in people with dementia was recently assessed by a Cochrane systematic review conducted by Abraha et al (16). Three trials including 144 patients were considered eligible for the study. In these studies, simulated presence therapy was compared with usual care, personalized music, a 'placebo' audiotape containing the voice of a person, and one-to-one social interaction performed by trained research assistants. Within each trial, the effect of simulated presence therapy (SPT) on behaviour, compared with usual care, was mixed and depended on the measure used. The quality of the studies included in this systematic review was extremely low, given the very low number of patients included and the inherent risk of bias. Therefore, no firm conclusions concerning the efficacy of simulated presence therapy 
Table II. Autonomous robotic applications for patients with advanced dementia.

\begin{tabular}{|c|c|c|c|c|c|}
\hline Author (Refs.) & Year & $\begin{array}{l}\text { Evidence } \\
\text { type }\end{array}$ & Method & Treatment & Outcome \\
\hline Demange et al (14) & 2019 & Study & $\begin{array}{l}\text { Qualitative (five focus groups) } \\
\text { and quantitative (questionnaire } \\
\text { survey) approach }\end{array}$ & $\mathrm{PARO}^{\circledR}$ robot & $\begin{array}{l}\text { Framework for the use of } \\
\text { the PARO }{ }^{\circledR} \text { robot in the } \\
\text { management of acute pain } \\
\text { in persons with dementia }\end{array}$ \\
\hline Valentí et al (15) & 2015 & Study & $\begin{array}{l}\text { Robot (NAO), pet robot } \\
\text { (PARO) or real animal (dog) } \\
\text { nursing home: one of the three } \\
\text { parallel therapeutic arms } \\
\text { CONTROL, PARO and NAO } \\
\text { (Phase 1) and CONTROL, } \\
\text { PARO, and DOG (Phase 2); day } \\
\text { care center, all patients NAO } \\
\text { (Phase 1) PARO (Phase 2). }\end{array}$ & $\begin{array}{l}3 \text { months of } \\
2 \text { days/week } \\
\text { therapy sessions }\end{array}$ & $\begin{array}{l}\text { Phase 1: improvement } \\
\text { in the NPI irritability and } \\
\text { the NPI total score; Phase } 2 \text { : } \\
\text { no differences at follow-up }\end{array}$ \\
\hline Abraha et al (16) & 2020 & Review & $\begin{array}{l}\text { Three trials including } \\
144 \text { patients }\end{array}$ & $\begin{array}{l}\text { Simulated } \\
\text { presence therapy }\end{array}$ & No firm conclusion \\
\hline Moyle et al (17) & 2015 & $\begin{array}{l}\text { Cluster- } \\
\text { randomized } \\
\text { controlled } \\
\text { trial }\end{array}$ & $\begin{array}{l}\text { Three treatment groups: } \\
\text { PARO }^{\circledR}, \text { Plush-Toy (non- } \\
\text { robotic PARO }{ }^{\circledR} \text { ) or usual care }\end{array}$ & $\begin{array}{l}10 \text { weeks of } 3 \text { non- } \\
\text { facilitated } 15-\text { min } \\
\text { sessions with PARO } \\
\text { or PlushToy each }\end{array}$ & Results yet to be published \\
\hline Astell et al (18) & 2019 & Study & $\begin{array}{l}\text { Summarizes key areas of } \\
\text { technology development; } \\
\text { identifies future directions } \\
\text { and implications }\end{array}$ & - & $\begin{array}{l}\text { Urges an immediate policy, } \\
\text { funding, and practice } \\
\text { change, for better risk } \\
\text { reduction, prevention, and } \\
\text { early detection }\end{array}$ \\
\hline Atee et al (19) & 2018 & $\begin{array}{l}\text { 2-week } \\
\text { observational } \\
\text { study }\end{array}$ & $\begin{array}{l}\text { Electronic Pain Assessment } \\
\text { Tool }\end{array}$ & - & $\begin{array}{l}\text { Good reliability properties, } \\
\text { and appropriate to use in } \\
\text { residents with advanced } \\
\text { dementia }\end{array}$ \\
\hline Hall et al (20) & 2017 & $\begin{array}{l}\text { Embedded } \\
\text { multiple-case } \\
\text { study }\end{array}$ & $\begin{array}{l}36 \text { semi-structured } \\
\text { interviews with staff, relatives, } \\
\text { and residents; } 175 \text { h of } \\
\text { observation; resident care } \\
\text { record review }\end{array}$ & - & $\begin{array}{l}\text { Use of monitoring } \\
\text { technologies encouraged if } \\
\text { perceived as safety } \\
\text { enhancing }\end{array}$ \\
\hline Bossen et al (21) & 2015 & Review & $\begin{array}{l}\text { Evaluation of online and } \\
\text { internet-based technology } \\
\text { use in monitoring and support }\end{array}$ & - & $\begin{array}{l}\text { Positive impact of } \\
\text { telemedicine and smart } \\
\text { technologies on helping } \\
\text { caregivers and reducing costs }\end{array}$ \\
\hline Bharucha et al (22) & 2009 & Review & $\begin{array}{l}\text { Review of intelligent cognitive } \\
\text { devices, physiologic and } \\
\text { environmental sensors, and } \\
\text { advanced integrated sensor } \\
\text { networks }\end{array}$ & - & $\begin{array}{l}\text { Computational and ethical } \\
\text { challenges with the } \\
\text { development of intelligent } \\
\text { assistive devices }\end{array}$ \\
\hline Beuscher et al (23) & 2017 & Study & $\begin{array}{l}\text { Use of socially assistive robots } \\
\text { (NAO humanoid robot) }\end{array}$ & - & $\begin{array}{l}\text { The need for further studies } \\
\text { on the role of socially } \\
\text { assistive robots }\end{array}$ \\
\hline Koutentakis et al (24) & 2020 & Review & $\begin{array}{l}\text { Evaluation of socially assistive } \\
\text { robots }\end{array}$ & 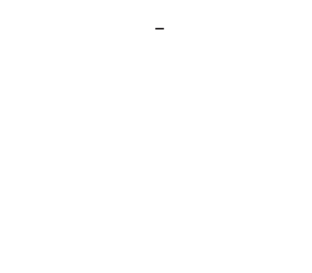 & $\begin{array}{l}\text { A socially assistive robot } \\
\text { could perform almost all the } \\
\text { functions desired of } \\
\text { Alzheimer's disease-related } \\
\text { dementia patients and their } \\
\text { caregivers }\end{array}$ \\
\hline
\end{tabular}


Table II. Continued.

\begin{tabular}{|c|c|c|c|c|c|}
\hline Author (Refs.) & Year & $\begin{array}{l}\text { Evidence } \\
\text { type }\end{array}$ & Method & Treatment & Outcome \\
\hline Pirhonen et al (25) & 2020 & Study & $\begin{array}{l}\text { Impact of social robots and } \\
\text { communicating technology }\end{array}$ & - & $\begin{array}{l}\text { Social robots could alleviate emotional } \\
\text { and social loneliness in assisted living } \\
\text { (ethical concerns) }\end{array}$ \\
\hline Majumder et al (26) & 2017 & Review & $\begin{array}{l}\text { Evaluation of data on smart } \\
\text { home-based remote healthcare } \\
\text { technologies }\end{array}$ & - & $\begin{array}{l}\text { Useful comprehensive information is } \\
\text { provided by smart homes }\end{array}$ \\
\hline Dang et al (27) & 2017 & Study & $\begin{array}{l}\text { Intelligent interactive care } \\
\text { system based on a multimodal } \\
\text { deep neural network }\end{array}$ & - & Accurate algorithm for recognition \\
\hline Cipriani and Fiorino (28) & 2020 & Study & $\begin{array}{l}\text { Summary of the events that } \\
\text { occurred in Italy during the } \\
\text { beginning of the SARS-CoV2 } \\
\text { pandemic, with the focus on } \\
\text { older age groups }\end{array}$ & - & $\begin{array}{l}\text { Dementia as one of the most frequent } \\
\text { comorbidities in deceased patients with } \\
\text { COVID19; discrimination based on } \\
\text { personal characteristics (such as age or } \\
\text { disability) was inadmissible }\end{array}$ \\
\hline
\end{tabular}

for treating behavioural and psychological symptoms and improving the quality of life of people with dementia could be drawn (16).

Moyle et al (17) proposed to evaluate the effect of the PARO $^{\circledR}$ robot, a Plush-toy or usual care on apathy, agitated behaviours, loneliness, and depression in 380 patients with dementia aged 60 years or more. The secondary outcomes of this trial included sleep duration, step count, changes in psychotropic medication use, change in treatment costs, and staff and family perceptions of the PARO robot or Plush-Toy. To date, the results of this study have yet to be published.

In their study, Astell et al (18) summarized the existing data in the literature up to 2019, on the impact of technology development on the management of dementia and identified future directions and implications. The authors focused on specific areas related to the evaluation and treatment of patients with dementia, namely: Diagnosis, assessment and monitoring, maintenance of function of patients with dementia, leisure and activities of these patients, caregiving and management, and future directions. They concluded that despite the rapid pace of innovations in the field of technology, urgent change was required in services and policies. Existing technology can collect prospective data, model risk, and provide supportive monitoring for patients with dementia.

Atee et al (19) conducted a 2-week observational study on a population of 10 patients with moderate to severe dementia and examined the inter-rater reliability of the electronic Pain Assessment Tool (ePAT) among evaluators when assessing pain. Secondary outcomes included the assessment of the relationship between total instrument scores and facial scores, as determined by the automated facial expression analysis. They found excellent agreement on overall total scores [coefficient of concordance 0.92 (95\% CI: 0.85-0.96)] at rest, but only moderate $(\kappa=0.59)$ on categorical scores upon movement. Based on these results, the authors concluded that the ePAT demonstrated favorable reliability properties, supporting its use in patients with advanced dementia (19).
Hall et al (20) conducted a study assessing enablers and obstacles in implementing monitoring technologies in care homes. The study included 24 staff members, nine residents, and nine relatives. They revealed that the most important reason for using monitoring technologies was to improve safety and increase freedom of residents, despite concerns related to ethical aspects (e.g., resident privacy). Setbacks were mostly related to the difficult cooperation of residents and the insufficient involvement of the staff in understanding the technologies. Other drawbacks included the frequently generated alarms that placed a burden upon staff and the lack of positive perception of some technologies by the staff members as useful complements to standard care. Collectively, the authors concluded that if the technology is perceived as enhancing the safety of residents, it may be accepted by the residential home staff, allowing residents to benefit from its advantages (20).

In their review article, Bossen et al (21) assessed the current role of smart technologies in supporting family caregivers of patients with dementia. Following the brief summary of the costs and the negative outcomes of caregiving, the authors presented the positive role of telemedicine and e-health, internet-based technology, and the support of caregivers through technology. The current roles of the monitoring systems were described. Potential challenges to their adoption were also discussed. Future directions and cutting-edge technologies were briefly mentioned as well. The authors concluded that telemedicine and smart technologies have an important potential in helping caregivers of patients with dementia and reducing healthcare costs (21).

Bharucha et al (22) assessed the existing evidence up to 2009 in several databases (computer science, engineering, and medical) that assessed the role of intelligent cognitive devices, physiologic and environmental sensors, and advanced integrated sensor networks in facilitating the healthcare for patients with dementia. The search strategy of authors identified a total of 58 technologies (both basic and advanced) with potential applications to dementia care. However, no clinical 
trial had been conducted up to the date of the publication of the review of the authors, that provided evidence-based arguments supporting the use of these technologies in the healthcare of patients with dementia. The authors identified 11 cognitive orthotics, 15 environmental sensors, 10 physiological sensors, and 22 advanced integrated sensor systems, with six studies assessing the development of memory aids. The authors concluded that intelligent assistive devices existent at that time could be applied in helping patients with dementia, despite remaining computational and ethical challenges.

Beuscher et al (23) evaluated the potential role of socially assistive robots in providing efficient and safe healthcare. Of the 19 participants included in this study, 11 had a one-to-one interaction with the NAO robot (a medium-sized humanoid robot of $58 \mathrm{~cm}$ and $4.3 \mathrm{~kg}$ ). Overall, the robot was well accepted, with participants rating it as easy to understand (68\%), having a pleasant voice (74\%), capable of hearing and understanding its speech $(79 \%)$, capable of keeping them interested (95\%), and having a pleasant appearance (86\%). However, only $63 \%$ rated the interaction with the robot as comfortable. The authors concluded that although socially assistive robots have an important potential in assisting health care providers in caring for older adults in physical, cognitive, and social activities, future studies were still required to precisely indicate their role in the care of elderly patients (23).

Koutentakis et al (24) conducted a review of the currently existing literature up to 2020 on socially assistive robots and their potential benefit in alleviating care for patients with Alzheimer's disease and Alzheimer's disease-related dementia. The authors presented the existing evidence of the efficacy of socially assistive robots, the acceptance, needs, and preference, and the emotion recognition and the response of these robots. They subsequently described the design and electronics of such robots, with the software used and their features. The authors concluded that due to the increasing life expectancy, a higher number of individuals will require care and support during their advanced period of life, particularly those with dementia. Socially assistive robots could be of invaluable help in the future (24).

Pirhonen et al (25) conducted a study on the impact of social robots and communicating technology in decreasing social and emotional loneliness in elderly residents. Assessed aspects were those included in the analytical frame built on Robert Weiss' division of relational functions: Social integration, attachment, reassurance of worth, opportunity for nurturance, guidance in stressful situations, and sense of reliable alliance. The authors identified that social robots can positively influence both social and emotional loneliness in this population. However, ethical concerns related to lack of human contact and deception still need to be considered before using social robots when caring for the elderly (25).

Majumder et al (26) analyzed the existing data on smart home-based remote healthcare technologies in their comprehensive review. They discussed the role of several wearable Wireless Body Area Network (WBAN), implantable WBAN, and remote health monitoring WBAN, with the emphasis on remote health monitoring. The effect of the Internet on healthcare and Internet-connected homes was discussed. Smart monitoring systems for the elderly and people with disabilities were presented and analyzed. Prototypes for smart homes for elderly healthcare were subsequently presented, and commercial solutions were offered. The authors concluded that smart homes could provide useful comprehensive information about the overall health status of the elderly through continuous monitoring.

Dang et al (27) described in their study, an intelligent interactive care system based on a multimode deep neural network, addressing the interaction with patients with dementia. Information on motion and mental features was acquired using depth images and electroencephalograms. The authors proposed an algorithm that simplified the process of recognition and achieved a high accuracy and recognition rate, of $>90 \%$, for both shuffled and continuous datasets.

Cipriani and Fiorino (28) described the outburst of the COVID-19 pandemic in Italy in early 2020. They presented the reported mortality rate of $12.2 \%$, which was even higher in elderly patients aged 80 to 89 years old which was $31 \%$. One of the most common comorbidities (11.9\%) of deceased patients with COVID-19 was dementia. Ethical aspects related to the admittance of patients with severe COVID-19 to the Intensive Care Unit, such as an age limit or the presence of dementia, were mentioned. An important question was raised concerning the criteria of providing non-palliative care to patients in need, in an overwhelmed medical system, and who should be left to succumb to this disease (26). The authors expressed their direct discontent about triage of patients based on characteristics such as age and disability (28).

The continuously growing number of individuals with dementia poses a major challenge for global public health (29). The integration of robotics into dementia care offers new possibilities for improving the lives of patients and easing the burden on caregivers and healthcare services $(24,30)$.

Generally, there are favorable benefits from robot-assisted activities to warrant further research in this field (24,31-33). However, the benefits these robots may provide are determined by the individual characteristics of the patient, particularly the degree of cognitive impairment and the presence or lack of prior technology experience. All the studies concerning autonomous AI-based applications included in this systematic review revealed that the method is feasible for clinical practice.

Our study has several strengths. First, to the best of our knowledge, this is the first systematic review to perform a comparative analysis between traditional nursing techniques and autonomous robotic applications used on patients with advanced stages of dementia. Second, the subject of this systematic review is of major relevance due to the increasing number of patients with dementia, the economic burden, and the lack of qualified personnel. Third, the COVID-19 pandemic and the risk of infection with the COVID-19 virus, both for the patients, relatives, and medical personnel, render autonomous AI-based applications for the care of patients with dementia a feasible cost-efficient solution (34).

This review has several limitations. The first limitation is the insufficient number of patients with dementia used for training of the AI-based applications. Second, was the lack of studies with a comparative analysis of distinct technologies, and thereby, the inability to find clear evidence concerning the best AI-based application for patients with dementia.

The implementation of these technical possibilities following the diagnosis of dementia and their permanent 
adaptation to the stages of disease evolution will permit training of patients in the management of their suffering.

\section{Conclusions}

Significant evidence was revealed, demonstrating that autonomous robotic applications used for patients with advanced stages of dementia are a feasible, cost-efficient solution and represent a benefit for the patients and the healthcare system.

\section{Acknowledgements}

Not applicable.

\section{Funding}

No funding was received.

\section{Availability of data and materials}

Data sharing is not applicable to this article, as no datasets were generated or analyzed during the current study.

\section{Authors' contributions}

LD suggested the methodology and searched the literature. SLP contributed to the writing of the manuscript and searched the literature. MB contributed to the writing of section on the traditional nursing techniques. LM contributed to the writing of section on the autonomous robotic applications. AI analyzed the results and revised the manuscript. AI and SLP confirm the authenticity of all the raw data. LCP contributed to the writing of manuscript. LPD revised the manuscript. MFS revised the manuscript and contributed to the writing of the manuscript. DLD analyzed the results. All authors read and approved the final version of the manuscript.

\section{Ethics approval and consent to participate}

Not applicable.

\section{Patient consent for publication}

Not applicable.

\section{Competing interests}

The authors declare that they have no competing interests.

\section{References}

1. Gale SA, Acar D and Daffner KR: Dementia. Am J Med 131: 1161-1169, 2018.

2. Prince M, Bryce R, Albanese E, Wimo A, Ribeiro W and Ferri CP: The global prevalence of dementia: A systematic review and metaanalysis. Alzheimers Dement 9: 63-75.e2, 2013.

3. Lopez OL and Kuller LH: Epidemiology of aging and associated cognitive disorders: Prevalence and incidence of Alzheimer's disease and other dementias. Handb Clin Neurol 167: 139-148, 2019.

4. Wolters FJ and Ikram MA: Epidemiology of dementia: The Burden on society, the challenges for research. Methods Mol Biol 1750: 3-14, 2018.
5. Cooper C, Tandy AR, Balamurali TB and Livingston G: A systematic review and meta-analysis of ethnic differences in use of dementia treatment, care, and research. Am J Geriatr Psychiatry 18: 193-203, 2010.

6. Husebo BS, Ballard C, Sandvik R, Nilsen OB and Aarsland D: Efficacy of treating pain to reduce behavioural disturbances in residents of nursing homes with dementia: Cluster randomised clinical trial. BMJ 343: d4065, 2011.

7. Sampson EL, Candy B and Jones L: Enteral tube feeding for older people with advanced dementia. Cochrane Database Syst Rev: Apr 15, 2009 (Epub ahead of print). doi: 10.1002/14651858. CD007209.pub2.

8. Skovdahl K, Sörlie V and Kihlgren M: Tactile stimulation associated with nursing care to individuals with dementia showing aggressive or restless tendencies: An intervention study in dementia care. Int J Older People Nurs 2: 162-170, 2007.

9. Ridder HM, Stige B, Qvale LG and Gold C: Individual music therapy for agitation in dementia: An exploratory randomized controlled trial. Aging Ment Health 17: 667-678, 2013.

10. Murphy E, Froggatt K, Connolly S, O'Shea E, Sampson EL, Casey D and Devane D: Palliative care interventions in advanced dementia. Cochrane Database Syst Rev 12: CD011513, 2016.

11. Aasmul I, Husebo BS and Flo E: Staff distress improves by treating pain in nursing home patients with dementia: Results from a cluster-randomized controlled trial. J Pain Symptom Manage 52: 795-805, 2016.

12. Birkenhäger-Gillesse EG, Kollen BJ, Zuidema SU and Achterberg WP: The 'more at home with dementia' program: A randomized controlled study protocol to determine how caregiver training affects the well-being of patients and caregivers. BMC Geriatr 18: 252, 2018.

13. Sánchez-Valdeón L, Fernández-Martínez E, Loma-Ramos S, López-Alonso AI, Bayón Darkistade E and Ladera V: Canine-Assisted therapy and quality of life in people with Alzheimer-type dementia: Pilot study. Front Psychol 10: 1332, 2019.

14. Demange M, Pino M, Kerherve H, Rigaud AS and CantegreilKallen I: Management of acute pain in dementia: A feasibility study of a robot-assisted intervention. J Pain Res 12: 1833-1846, 2019.

15. Valentí Soler M, Agüera-Ortiz L, Olazarán Rodríguez J, Mendoza Rebolledo C, Pérez Muñoz A, Rodríguez Pérez I, Osa Ruiz E, Barrios Sánchez A, Herrero Cano V, Carrasco Chillón L, et al: Social robots in advanced dementia. Front Aging Neurosci 7: 133, 2015.

16. Abraha I, Rimland JM, Lozano-Montoya I, Dell'Aquila G, Velez-Diaz-Pallares M, Trotta FM, Cruz-Jentoft AJ and Cherubini A: Simulated presence therapy for dementia. Cochrane Database Syst Rev 4: CD011882, 2020.

17. Moyle W, Beattie E, Draper B, Shum D, Thalib L, Jones C, O'Dwyer S and Mervin C: Effect of an interactive therapeutic robotic animal on engagement, mood states, agitation and psychotropic drug use in people with dementia: A cluster-randomised controlled trial protocol. BMJ Open 5: e009097, 2015.

18. Astell AJ, Bouranis N, Hoey J, Lindauer A, Mihailidis A, Nugent C, and Robillard JM; Technology and Dementia Professional Interest Area: Technology and dementia: The future is now. Dement Geriatr Cogn Disord 47: 131-139, 2019.

19. Atee M, Hoti K, Parsons R and Hughes JD: A novel pain assessment tool incorporating automated facial analysis: Interrater reliability in advanced dementia. Clin Interv Aging 13: 1245-1258, 2018.

20. Hall A, Wilson CB, Stanmore E and Todd C: Implementing monitoring technologies in care homes for people with dementia: A qualitative exploration using Normalization process theory. Int J Nurs Stud 72: 60-70, 2017.

21. Bossen AL, Kim H, Williams KN, Steinhoff AE and Strieker M: Emerging roles for telemedicine and smart technologies in dementia care. Smart Homecare Technol Telehealth 3: 49-57, 2015.

22. Bharucha AJ, Anand V, Forlizzi J, Dew MA, Reynolds CF III, Stevens S and Wactlar H: Intelligent assistive technology applications to dementia care: Current capabilities, limitations, and future challenges. Am J Geriatr Psychiatry 17: 88-104, 2009.

23. Beuscher LM, Fan J, Sarkar N, Dietrich MS, Newhouse PA, Miller KF and Mion LC: Socially assistive robots: Measuring older adults' perceptions. J Gerontol Nurs 43: 35-43, 2017.

24. Koutentakis D, Pilozzi A and Huang X: Designing socially assistive robots for Alzheimer's disease and related dementia patients and their caregivers: Where we are and where we are headed. Healthcare (Basel) 8: 73, 2020. 
25. Pirhonen J, Tiilikainen E, Pekkarinen S, Lemivaara M and Melkas H: Can robots tackle late-life loneliness? Scanning of future opportunities and challenges in assisted living facilities. Futures 124: 102640, 2020

26. Majumder S, Aghayi E, Noferesti M, Memarzadeh-Tehran H, Mondal T, Pang Z and Deen MJ: Smart homes for elderly healthcare-recent advances and research challenges. Sensors (Basel) 17: 2496, 2017.

27. Dang X, Kang B, Liu X and Cui G: An interactive care system based on a depth image and EEG for aged patients with dementia. J Healthc Eng 2017: 4128183, 2017.

28. Cipriani $\mathrm{G}$ and Fiorino MD: Access to care for dementia patients suffering from COVID-19. Am J Geriatr Psychiatry 28: 796-797, 2020.

29. Ienca M, Jotterand F, Vică C and Elger B: Social and assistive robotics in dementia care: Ethical recommendations for research and practice. Int J of Soc Robotics 8: 565-573, 2016.

30. Cheng ST: Dementia caregiver burden: A research update and critical analysis. Curr Psychiatry Rep 19: 64, 2017.
31. Hung L, Liu C, Woldum E, Au-Yeung A, Berndt A, Wallsworth C, Horne N, Gregorio M, Mann J and Chaudhury H: The benefits of and barriers to using a social robot PARO in care settings: A scoping review. BMC Geriatr 19: 232, 2019.

32. Martin F, Aguero C, Canas JM, Abella G, Benitez R, Rivero S, Valenti M and Martinez-Martin P: Robots in therapy for dementia patients. J Physical Agents 7: 49-56, 2017.

33. Papadopoulos I, Koulouglioti C, Lazzarino R and Ali S: Enablers and barriers to the implementation of socially assistive humanoid robots in health and social care: A systematic review. BMJ Open 10: e033096, 2020.

34. Lima MR, Wairagkar M, Natarajan N, Vaitheswaran S and Vaidyanathan R: Robotic telemedicine for mental health: A multimodal approach to improve human-robot engagement. Front Robot AI 8: 618866, 2021.

(c) (7) $($ This work is licensed under a Creative Commons Attribution-NonCommercial-NoDerivatives 4.0 International (CC BY-NC-ND 4.0) License. 